\title{
Free radical scavenging capacity, anticandicidal effect of bioactive compounds from Sida Cordifolia L., in combination with nystatin and clotrimazole and their effect on specific immune response in rats
}

\author{
Maurice Ouédraogo $0^{1 *}$, Kiessoun Konaté ${ }^{2,4}$, Alexis Nicaise Lepengué ${ }^{3}$, Alain Souza ${ }^{4}$, Bertrand M'Batchi ${ }^{3,4}$ \\ and Laya L Sawadogo ${ }^{1}$
}

\begin{abstract}
Background: Infectious diseases caused by fungi are still a major threat to public health, despite numerous efforts by researchers. Use of ethnopharmacological knowledge is one attractive way to reduce empiricism and enhance the probability of success in new drug-finding efforts. In this work, the total alkaloid compounds (AC) from Sida cordifolia L. (Malvaceae) have been investigated for their free radical scavenging capacity, antifungal and immunostimulatory properties.
\end{abstract}

Method: The antifungal activity was investigated against five candida strains using the microplate dilution method and the Fractional Inhibitory Concentration Index (FICl) of compounds was evaluated. The antioxidant activity of the samples was evaluate using three separate methods, at last, the immunostimulatory effect on immunosuppressed wistar rats was performed.

Results: As for the antifungal activity, result varied according to microorganism. The results obtained in this antifungal activity were interesting and indicated a synergistic effect between alkaloid compounds and the antifungal references such as Nystatin and Clotrimazole. Antioxidant capacity noticed that the reduction capacity of DPPH radicals obtained the best result comparatively to the others methods of free radical scavenging. Our results showed a low immunostimulatory effect and this result could be explained by the lack of biologically active antioxidants such as polyphenol compounds lowly contained in the alkaloid compounds.

Conclusion: The results of this study showed that alkaloid compounds in combination with antifungal references (Nystatin and Clotrimazole) exhibited antimicrobial effects against candida strains tested. The results supported the utilization of these plants in infectious diseases particularly in treatment of candida infections.

\footnotetext{
*Correspondence: ouedraogo_maurice@yahoo.fr

'Laboratory of Animal Physiology, University of Ouagadougou, 09 P.O. Box:

848, Ouagadougou 09, Burkina Faso

Full list of author information is available at the end of the article
} 


\section{Background}

Diseases due to pathogenic fungi represent a critical problem to human health and they are one of the main causes of morbidity and mortality worldwide [1]. The emergence of pathogens resistant to antibiotics as a result of their excessive use in clinical and veterinary applications represents a serious public health concern [2]. In the last three decades, pathogenic resistant fungi particularly candida strains, have caused major health problems throughout the world in women although the pharmacological industries produced quantities of antibiotics. Unfortunately, the resistance of fungi to these drugs is increasingly important. The search for plants with antifungal activity has gained increasing importance in recent years due to the development of resistance. On the other hand, it is known that free radicals play a fundamental role in several diseases. The biochemical damages caused by free radicals to cells and tissues, lead to the development of diseases such as arteriosclerosis, high blood pressure, cancer, inflammation, renal failure, liver disease [3].

Medicinal plants are largely used either for the prevention, or for the curative treatment of several diseases. Among the properties behind these virtues, the antioxidant activity holds the first place [4-6]. Plants used in traditional medicine may constitute an important source of new biologically active compounds. It is estimated that there are about 2,500000 species of higher plants and the majority of these plants have not been studies for their pharmacological activities [7]. According to world Health Organization (WHO), 80\% of the world population still relies mainly on substances extract from plants to cure diseases [8]. The fact that microorganisms nowadays tend to develop resistance towards drugs, coupled to the undesirable side effects of certain antibiotics offer considerable potential for the development of new effective antimicrobial and antioxidant agents, medicinal plants are a prolific source. Scientific experiments on the antimicrobial properties of plant components were first documented in the late $19^{\text {th }}$ century [9]. The shortcomings of the drugs available today propel the discovery of new pharmacotherapeutic agents in herbal medicine [10]. Amongst the medicinal plants investigated in our research team, the family Malvaceae is largely represented and some of these plants as Sida cordifolia L. (Malvaceae). A decoction of this Malvaceae is locally used in the treatment of coughs, rheumatic and abdominal pain, and diarrhea while the leaf decoction is used in the treatment of fever and to prevent miscarriage [11].

Some biological activities of these Malvaceae have been reported [12]. However, to the best of our knowledge, no information of alkaloid fractions on its antioxidant, antifungal activities and immunostimulatory capacity are available.
Many fungi are parasite on plants and animals (including humans) causing serious diseases in human such as candidose among others. Furthermore, persons with immune-deficiencies are particularly susceptible to diseases by candida [13]. Supported especially a reduction in the immune system due to a lack of antioxidants, this study was therefore designed to evaluate the possible beneficial antioxidant, anticandicidal and immunostimulatory potencies of the total alkaloid fractions from Sida cordifolia L. (Malvaceae). Our results would strengthen the traditional use of this Malvaceae and contribute to the acceptance of traditional medicine for the best management of candidoses of which the women suffer much nowadays.

\section{Materials}

\section{Plant materials}

Sida cordifolia L., was collected in August 2008 in Gampela, $25 \mathrm{Km}$ east of Ouagadougou, capital of Burkina Faso. The plant was botanically identified by Prof. Millogo-Rasolodimby from the plants Biology Department of the University of Ouagadougou. Voucher specimen was deposited in the Herbarium of the La.B.E.V. (Laboratory of Plant Ecology and Biology, UFR/SVT of University of Ouagadougou) from the University of Ouagadougou.

\section{Animals handling}

Swiss NMRI mice (25-30 g) and adult albinos Wistar rats (195-200 g) of both sexes were used for this study. All animals were housed in cages under controlled conditions of 12 -h light/and $12 \mathrm{~h}$ without light and $25^{\circ} \mathrm{C}$. They received pellets of food enriched with $20 \%$ protein and water ad libitum. They were deprived of food for $15 \mathrm{~h}$ (but with access to drinking water) and weighed before the experiments. Experiments on the animals were performed according to the protocols already approved by the Institute of Health Sciences Research/University of Ouagadougou (Burkina Faso) and met the international standards for animal study [14].

\section{Test organisms}

The studies microorganisms included reference strains of Candida albicans ATCC 9002, Candida albicans ATCC 2091, Candida parapsilosis ATCC 22019, Candida tropicalis ATCC 750, Candida Krusei ATCC 6258. Fungal strains were maintained on agar slant at $4{ }^{\circ} \mathrm{C}$ and sub-cultured on a fresh appropriate agar plates 24 $\mathrm{h}$ prior to any antifungal activity. Sabouraud Glucose Agar was used for the activation of fungi. The Mueller Hinton Broth (MHB) was used for the MIC and MFC determinations. 


\section{Methods}

Preparation of extract for acute toxicity study

Fifty grams of powdered plant materials (dried in laboratory condition) was extracted with $500 \mathrm{ml}$ of acetone $80 \%$ (400 ml acetone $+100 \mathrm{ml}$ water) for $24 \mathrm{~h}$ under mechanic agitation (SM 25 shaker, Edmund BÜHLER, Germany) at room temperature. After filtration, acetone was removed under reduced pressure in a rotary evaporator (BÜCHI, Rotavopor R-200, Switzeland) at approximately $40^{\circ} \mathrm{C}$ and freeze-dried (Telstar Cryodos 50 freeze-dryer). The extract was weighed before packing in waterproof plastic flasks and stored at $4^{\circ} \mathrm{C}$ until use.

\section{Extraction of alkaloid compounds}

The harvested plant materials fresh (broken into leaf stems) were dried in the laboratory at room temperature $\left(20-25^{\circ} \mathrm{C}\right)$, afterwards samples were ground and made alkaline and $50 \mathrm{~g}$ were used with $28 \%$ ammonia and extracted with chloroform at room temperature for a total period of $24 \mathrm{~h}$ and then the extract was partitioned between $5 \% \mathrm{HCl}$ and Chloroform. The aqueous phase was made alkaline again with ammonia and partitioned between water and chloroform. Finally chloroform was totally evaporated from the organic phase to form the alkaloids powder [15].

\section{Antioxidant activity determination DPPH radical method}

Radical scavenging activity of plant fractions against stable DPPH (2, 2'-diphenyl-1-picrylhydrazyl, Fluka) was determined with a UV/visible light spectrophotometer (CECIL CE 2041, CECIL Instruments, England) at $517 \mathrm{~nm}$ as described by [16]. Fraction solutions were prepared by dissolving $10 \mathrm{mg}$ of dry extract in $10 \mathrm{ml}$ of methanol. The samples were homogenized in an ultrasonic bath. $0.5 \mathrm{ml}$ of aliquots which were prepared at different concentrations from each sample of fraction was mixed with $1 \mathrm{ml}$ of methanolic DPPH solution $(20 \mathrm{mg} / \mathrm{ml})$. After $15 \mathrm{~min}$ in the dark at room temperature, the decrease in absorption was measured. All experiments were performed in triplicate and expressed in mmol Ascorbic Acid Equivalent per $\mathrm{g}$ of fraction $\left(\mathrm{Y}=-16.815 \mathrm{x}+6.8373 ; \mathrm{R}^{2}=0.9976\right)$. Quercetin was used as positive control $[17,18]$.

\section{ABTS radical cation decolorization assay}

For ABTS radical cation decolorization assay, the procedure followed the method of [16]. ABTS was dissolved in water to a $7 \mathrm{mM}$ concentration. ABTS radical cation $\left(\mathrm{ABTS}^{+}\right)$was produced by reacting ABTS stock solution with $2.45 \mathrm{mM}$ potassium persulfate (final concentration) and allowing the mixture to stand in the dark at room temperature for $12 \mathrm{~h}$ before use. This mixture was diluted with ethanol to give an absorbency of $0.7 \pm 0.02$ units at $734 \mathrm{~nm}$ using a UV/visible light spectrophotometer
(CECIL CE 2041, CECIL Instruments, England). For our study, we used $10 \mu \mathrm{L}$ of the diluted sample $\left(1 \mathrm{mgmL}^{-1}\right.$ in methanol) which was allowed to react with $990 \mu \mathrm{L}$ of fresh $\mathrm{ABTS}^{+}$solution and the absorbance was taken $6 \mathrm{~min}$ exactly after initial mixing. Ascorbic acid was used as standard $\left(Y=-0.0342 x+0.634 ; R^{2}=0.9996\right)$ and the capacity of free radical scavenging was expressed as mmol Ascorbic Acid Equivalent per g of fraction. Quercetin, a reference compound was used as positive control.

\section{$\mathrm{Fe}^{3+}$ to $\mathrm{Fe}^{2+}$ reduction activity (FRAP)}

The FRAP assay was performed according to [19]. $0.5 \mathrm{~mL}$ of each fraction (1 mgmL-1) was mixed with $1.25 \mathrm{~mL}$ of phosphate buffer $(0.2 \mathrm{M}, \mathrm{pH}$ 6.6) and 1.25 $\mathrm{mL}$ of aqueous potassium hexacyanoferrate $\left[\mathrm{K}_{3} \mathrm{Fe}(\mathrm{CN})_{6}\right]$ solution (1\%). After $30 \mathrm{~min}$ incubation at $50^{\circ} \mathrm{C}, 1.25 \mathrm{~mL}$ of trichloroacetic acid (10\%) was added and the mixture was centrifuged at $2000 \times \mathrm{g}$ for $10 \mathrm{~min}$. Then, the upper layer solution $(0.625 \mathrm{~mL})$ was mixed with distilled water $(0.625 \mathrm{~mL})$ and a freshly prepared $\mathrm{FeCl}_{3}$ solution $(0.125 \mathrm{~mL}, 0.1 \%)$. Absorbencies were read at $700 \mathrm{~nm}$ on a UV/visible light spectrophotometer (CECIL CE 2041, CECIL Instruments, England) and Ascorbic acid was used to produce the calibration curve $(Y=0.008 x-$ $\left.0.0081 ; \mathrm{R}^{2}=0.9999\right)$. The iron $\left(\mathrm{Fe}^{3+}\right)$ reducing activity determination was performed in triplicate and expressed in mmol Ascorbic Acid Equivalent per $g$ of fraction. Troloc, a reference compound was used as positive control [20].

\section{In vitro antifungal activity Preparation of inocula}

The fungal strains grown on nutrient agar (Muller Hinton broth) at $35^{\circ} \mathrm{C}$ for $72 \mathrm{~h}$ were suspended in a saline solution $(0.9 \%, \mathrm{w} / \mathrm{v}) \mathrm{NaCl}$ and adjusted to a turbidity of 0.5 Mac Farland standard $\left(5 \times 10^{5} \mathrm{CFU} / \mathrm{ml}\right)$ [21].

\section{Preparation of fraction substances}

The stock solutions of AC were dissolved in $10 \%$ dimethylsulfoxide (DMSO) in water [21,22] at a final concentration of $800 \mu \mathrm{g} / \mathrm{ml}$. The stock solutions were sterilized by filtration through $0.22 \mu \mathrm{m}$ sterilizing Millipore express filter.

\section{Minimum inhibitory concentration (MIC) assay}

Minimum inhibitory concentration (MIC) was determined by the microdilution method in culture broth as recommended by $[21,23]$ with low modifications. 12 serial two-fold dilutions of AC solutions or conventional antibiotic were prepared as described before, to obtain final concentration ranges of $800-0.78125 \mu \mathrm{g} / \mathrm{ml}$ and $50-0.0488 \mu \mathrm{g} / \mathrm{ml}$ for $\mathrm{AC}$ and reference substances respectively. The last wells $\left(\mathrm{n}^{\circ} 12\right)$ served as sterility controls (contained broth only) or negative control 
(broth + inoculums). The 96-well micro-plates (NUNC, Danemark) containing $100 \mu \mathrm{L}$ of Mueller Hinton $(\mathrm{MH})$ broth were used. For each fungi strain, three columns of eleven wells to the micro-plate were used. Each well has getting: the culture medium + AC solution or Nystatin/ Clotrimazole or the combination of fraction solution with Nystatin/Clotrimazole + inoculum standardized at $5 \times 10^{5} \mathrm{CFU} / \mathrm{ml}(10 \mu \mathrm{l}$ of inocula) and INT $(50 \mu \mathrm{l}$; $0.2 \mathrm{mg} / \mathrm{ml}$ for $30 \mathrm{~min})$. The plates were sealed with parafilm, then agitated with a plate shaker to mix their contents and incubated at $35^{\circ} \mathrm{C}$ for $48 \mathrm{~h}$. All tests were performed in triplicate and the fungi activity was expressed as the mean of inhibitions produced. Viable microorganisms reduced the yellow dye to a pink colour. The MIC was defined as the lowest concentration of AC substance at which no colony was observed after incubation. So, the MIC was defined as the lowest concentration where no change was observed, indicating no growth of microorganism.

\section{Minimum fungicidal concentration (MFC)}

Minimum fungicidal concentration (MFC) was determined by the microdilution method in culture broth as recommended by $[21,23]$ with low modifications. Minimum fungicidal concentration (MFC) was determined by adding $50 \mu \mathrm{l}$ aliquots of the clear wells to $150 \mu \mathrm{l}$ of freshly prepared broth medium and incubating at $35^{\circ} \mathrm{C}$ for $48 \mathrm{~h}$. The MFC was regarded as the lowest concentration of test sample which did not produced a colour. All tests were performed in triplicates.

\section{Evaluation of the fractional inhibitory concentration index of AC}

The Muller Hinton agar dilution method was used to evaluate the Fractional Inhibitory Concentration Index (FICI) of AC and the tested anti-microbial standard as reported earlier [24,25]. Eleven (11) serial two-fold dilutions of AC solutions were prepared as described before, to obtain final concentration range of 800 to $0.78125 \mu \mathrm{g} / \mathrm{ml}$. A series of two-fold serial dilutions of Nystatin or Clotrimazole was also prepared in the same conditions as AC. In this way, antifungal standard dilutions were mixed with the appropriate concentration of $\mathrm{AC}$ solution thus obtaining a series of the combinations of conventional antifungal and $\mathrm{AC}$ solution. The concentrations prepared corresponded to 1-1/1024 of MIC values. The 96-well microplate (NUNC, Danemark) containing $100 \mu \mathrm{L}$ of Mueller Hinton $(\mathrm{MH})$ broth were used. For each fungal strain, three columns of eleven wells to the micro-plate were used. Each well has getting: the culture medium + combination of AC solution with Nystatin/Clotrimazole + inoculum standardized at $5 \times 10^{5} \mathrm{CFU} / \mathrm{ml}(10 \mu \mathrm{l}$ of inocula) and INT (50 $\mu \mathrm{l} ; 0.2 \mathrm{mg} / \mathrm{ml}$ for $30 \mathrm{~min}$ ). The plates were covered and incubated at $35^{\circ} \mathrm{C}$ for $48 \mathrm{~h}$. All tests were performed in triplicate and the fungicidal activity was expressed as the mean of inhibitions produced. Viable microorganisms reduced the yellow dye to a pink colour. The analysis of the combination of $\mathrm{AC}$ solution and antifungal references (Nystatin and Clotrimazole) was obtained by calculating the Fractional Inhibitory Concentration Index (FICI) as follows: $\mathrm{FICI}=(\mathrm{MICa}$ of $\mathrm{AC}$ in combination $/ \mathrm{MICa}$ alone $)+$ (MICb of the standard antifungal agent in combination/ $\mathrm{MICb}$ alone), where MICa (Minimal Inhibitory Concentration of $\mathrm{AC}$ ) and MICb (Minimal Inhibitory Concentration of Nystatin or Clotrimazole). The FICI was interpreted as follows: (1) a synergistic effect when FICI $=0.5$; (2) an additive or indifferent effect when FICI $>0.5$ and $<1$; (3) an antagonistic effect when $>1$ [21].

\section{Immunostimulatory potential of $A C$ on response immune specific}

Acute toxicity study in mice

Healthy male and female Swiss mice (20-30g) were randomly divided into 7 groups ( 1 control group and 6 treated assay groups) of 6 animals (3 male and 3 female). The animals were deprived of food but not water $15 \mathrm{~h}$ prior to the administration of the test suspension. The control group received intraperitoneally. $10 \%$ dimethylsulfoxide (DMSO) solution (in water). The general behaviour of the mice was observed at $120 \mathrm{~min}$ after the treatment. The animals were fed with food pellets and water ad libitum. They were screened for morbidity and mortality once a day for up 14 days. The number of survivors after the 14 days period was noted. The toxicological effect was assessed on the basis of mortality, which was expressed as the median lethal dose $\left(\mathrm{LD}_{50}\right)$. The $\mathrm{LD}_{50}$ (Lethal Dose 50 was determined according to the method of [26].

\section{Animals' treatment for immunostimulatory potential}

The animals were divided into 06 groups of six animals each one. Groups 1, 2 and 3 were used as controls groups.

Group 1. The rats received 10\% DMSO as control by oral way during 28 days.

Group 2. The rats received cyclosporin A as control ( $25 \mathrm{mg} / \mathrm{kg}$, by oral route) during 07 days (from $1^{\text {st }}$ to $7^{\text {th }}$ day) and then received DMSO $10 \%$ (from $8^{\text {th }}$ to $28^{\text {th }}$ day).

Group 3. The rats received concavanalin A ( $25 \mathrm{mg} / \mathrm{kg}$, by oral route) from $8^{\text {th }}$ to $28^{\text {th }}$ day

Group 4. The rats received extract of AC from Sida cordifolia (50 mg/kg bw.)

Group 5. the rats received extract of AC from Sida cordifolia $(100 \mathrm{mg} / \mathrm{kg} \mathrm{bw}$.

Group 6. The rats received extract of AC from Sida cordifolia $(200 \mathrm{mg} / \mathrm{kg}$ bw.) 
The animals of groups 2 to 6 initially received cyclosporin A ( $25 \mathrm{mg} / \mathrm{kg}$ bw oral route) $1^{\text {st }}$ to $7^{\text {th }}$ day in order to lower the immune system. The $28^{\text {th }}$ day, the animals were deprived of water and food during 15 hours [27].

\section{Assessment of immunostimulatory potential}

At the end of 28-days period, the animals were deprived of food for $15 \mathrm{~h}$ and blood samples were collected by cardiac puncture in two tubes for hematological and serologic parameters analysis. The blood samples (with heparin and without anticoagulant) were centrifuged at $3000 \mathrm{rpm}$ for $5 \mathrm{~min}$ to obtain plasma or serum. Hematological analyses were performed on whole blood, using automatic counter (Mindray Auto hematology Analyser BC-5500) to evaluate following parameters: total white blood cells (TWBC), total lymphocytes using automatic Counter System (SB FACS) serologic parameters (CD8 and CD4) were determined [27].

\section{Statistical analysis}

The data of antioxidant and antifungal activities were expressed as Mean \pm Standard deviation (SD) of three determinations. Statistical analysis (ANOVA with a statistical significance level set at $\mathrm{p}<0.05$ and linear regression) was carried out with XLSTAT 7.1. However, the data of immunostimulatory effect were expressed as Mean \pm Standard deviation (SD) of six determinations $(n=6)$. Results were analysed by one-way ANOVA followed by Dunnett's $t$-test using Prism 4 software. The level of significance was accepted at $\mathrm{p} \leq 0.05$.

\section{Results}

Free radical scavenging capacity DPPH radical method

Results are consigned in the (Table 1 ). The reduction capacity of DPPH radicals was determined by the decrease of the absorbance induced by antioxidant at $517 \mathrm{~nm}$, which is induced by antioxidant. The value is $6.63 \pm 0.10 \mathrm{mmoL}$ $\mathrm{AAE} / \mathrm{g}$ fractions. Control compound gave 13.76 \pm 0.26 $\mathrm{mmoL} \mathrm{AAE} / \mathrm{g}$ fraction for Quercetin. The different letters in the same column of Table 1 indicate significant difference $(\mathrm{P}<0.05)$ for our different fractions.

$\mathrm{Fe}^{3+}$ to $\mathrm{Fe}^{2+}$ reduction activity (FRAP)

For FRAP assay, the following value is $3.47 \pm 0.01 \mathrm{mmoL}$ $\mathrm{AAE} / \mathrm{g}$ fractions. Control compound gave $7.46 \pm 3.38 \mathrm{mmoL}$
AAE/g fractions for Trolox (Table 1). The different letters in the same column of Table 1 indicate significant difference $(\mathrm{P}<0.05)$ for our different fractions.

\section{ABTS radical cation decolorization assay}

For ABTS radical cation decolorization assay, the value is $3.90 \pm 0.03 \mathrm{mmoL} \mathrm{AAE} / \mathrm{g}$ fractions. The reference compound is Quercetin 7.81 $\pm 0.21 \mathrm{mmol} \mathrm{AAE} / \mathrm{g}$ fraction. We note that, the reduction capacity of DPPH radicals obtained the best result comparatively to the others methods of free radical scavenging; but comparatively to the reference compounds used we notice that the result is not interesting (Table 1). The different letters in the same column of Table 1 indicate significant difference $(\mathrm{P}<0.05)$ for our different fractions.

\section{In vitro antifungal activity}

Minimum inhibitory concentration (MIC) assay and Minimum fungicidal concentration (MFC)

As for the Minimum inhibitory concentration assay (MIC) and Minimum fungicidal concentration (MFC) of $\mathrm{AC}$ and their combination with antifungal references (Nystatin and Clotrimazole), result varied according to microorganism and results are summarize in Tables 2, 3 and 4. The MIC values of AC were ranged from 8.33 to $12.5 \mu \mathrm{g} / \mathrm{ml}$.

\section{Evaluation of the fractional inhibitory concentration index of fractions}

For FICI, our results indicate a synergistic effect between $\mathrm{AC}$ and the antifungal references (Nystatin and Clotrimazole) (Table 5 and Table 6).

\section{Acute toxicity study in mice}

About the acute toxicity study in mice, the value of LD50 was: $3.4 \mathrm{~g} / \mathrm{kg}$. The results of this study indicated that the extract of Sida cordifolia are low poisonous. During the 14 day period of acute toxicity evaluation, some signs of toxicity were observed, but they were all quickly reversible.

\section{Immunostimulatory potential of $A C$ on response immune specific}

At last, concerning the effect of alkaloid fractions on specific immune response, Figure 1 shows the effects of alkaloid compounds on the hematologic and serologic

Table 1 Antioxidant properties of AC from Sida cordifolia

\begin{tabular}{cccc}
\hline Fractions & DPPH $\mathbf{~ m m o L ~ A A E / g ~ f r a c t i o n ~}$ & FRAP mmoL/g fraction & ABTS mmoL AAE/g fraction \\
\hline AC/Sida cordifolia & $6.63 \pm 0.10$ & $3.47 \pm 0.001$ & $3.90 \pm 0.03$ \\
Quercetin & $13.76 \pm 0.26$ & Not determined & $7.81 \pm 0.21$ \\
Trolox & Not determined & $7.46 \pm 3.38$ & Not determined \\
\hline
\end{tabular}

mmoL AAE/g fraction: mmol equivalent Ascorbic Acid for $1 \mathrm{~g}$ dried fraction.

Values are Mean $\pm S D(n=3)$. Different letters in the same column indicate significant difference $(P<0.05)$ for $A C$. 
Table 2 Minimal Inhibitory Concentration (MIC) of AC from Sida cordifolia L., and antifungal references (Nystatin and Clotrimazole)

\begin{tabular}{cccc}
\hline Microorganisms & MIC $(\boldsymbol{\mu g} / \mathbf{m l})$ AC of Sida cordifolia & MIC $(\boldsymbol{\mu g} / \mathbf{m l})$ Nystatin & MIC $(\boldsymbol{\mu g} / \mathbf{m l})$ Clotrimazole \\
\hline Candida albicans ATCC 9002 & $10.42 \pm 3.61^{\mathrm{b}}$ & $4.17 \pm 1.80$ & $4.17 \pm 1.80$ \\
Candida albicans ATCC $\mathbf{2 0 9 1}$ & $8.33 \pm 3.61^{\mathrm{b}}$ & $4.17 \pm 1.80$ & $6.25 \pm 0.00$ \\
Candida parapsilosis ATCC 22019 & $12.5 \pm 0.00^{\mathrm{a}}$ & $6.25 \pm 0.00$ & $6.25 \pm 0.00$ \\
Candida krusei ATCC 6258 & $8.33 \pm 3.61^{\mathrm{c}}$ & $4.17 \pm 1.80$ & $4.17 \pm 1.80$ \\
Candida tropicalis ATCC 750 & $10.42 \pm 3.61^{\mathrm{b}}$ & $4.17 \pm 1.80$ & $6.25 \pm 0.00$ \\
\hline
\end{tabular}

Values are Mean $\pm S D(n=3)$. Different letters in the same column indicate significant difference $(P<0.05)$ for $A C$.

parameters of the rats. It is noticeable that the effect of the total alkaloid fractions concentrations of $50 \mathrm{mg} / \mathrm{kg}$, $100 \mathrm{mg} / \mathrm{kg}$ and $200 \mathrm{mg} / \mathrm{kg}$ bw involved a significant decrease of hematologic and serologic parameters $(\mathrm{p}<0.01)$ compared to the group controls. On hematological and serological parameters (Figure 1), there is actual evidence that cyclosporin A has an immunosuppressive potential and concavanalin A has an immunostimulatory property. The low increase in hematological and serological parameters of the test group 6, compared to the control group 2 (cyclosporin A control) allows to say that the total alkaloid fractions $(200 \mathrm{mg} / \mathrm{kg}$ bw; $\mathrm{p}<0.01)$ has a low immunostimulatory effect.

\section{Discussion}

Infectious diseases caused by fungi are still a major threat to public health, despite numerous efforts by researchers. Their impact is particularly large in developing countries due to the relative unavailability of medicines and the emergence of widespread drug resistance [28]. Use of ethnopharmacological knowledge is one attractive way to reduce empiricism and enhance the probability of success in new drug-finding efforts [29]. Validation and selection of primary screening assays are pivotal to guarantee sound selection of extracts or molecules with relevant pharmacological action and worthy following up [30]. The number of multi-drug resistant microbial strains and the appearance of strains with reduced susceptibility to antibiotics are continuously increasing. This increase has been attributed to indiscriminate use of broad-spectrum, immunosuppressive agent and ongoing epidemics of HIV infection [31]. The development of drug resistance in human pathogens against commonly used antibiotics and antifungal has necessitated a search for new antimicrobial substances. Higher plants produce diverse secondary metabolites with different biological activities. These natural compounds may be a source of compounds with antimicrobial effects and therefore possible candidates for the development of new antifungal agents [32,33].

On the toxicity of the extract, according to [34], pharmacological substances whole $\mathrm{LD}_{50}$ is less than $5 \mathrm{mg} / \mathrm{kg}$ body weight are classified in the range of highly toxic substances, those with a $\mathrm{LD}_{50}$ between $5 \mathrm{mg} / \mathrm{kg}$ body weight and $5000 \mathrm{mg} / \mathrm{kg}$ body weight are classified in the range of moderately toxic substances and those with the lethal dose is more than $5000 \mathrm{mg} / \mathrm{kg}$ body weight not toxic. In this fact, if we refer to this classification we could say that the extract of Sida cordifolia is moderately toxic and would be regarded as being safe or of low toxicity [35].

For the antioxidants properties, we have tested three methods for a best appreciation of our results; because a recent study demonstrates that there are differences between the test systems for the determination of the antioxidants properties [36]. The phytochemical analysis carried out on Sida cordifolia L., extract show that several polyphenol including flavonoids are found in its extracts [11]. Generally, the chemical structure of flavan3-ol family has good antioxidants response towards $\mathrm{DPPH}^{*}$ radical. The hydrogen donating substituents (hydroxyl groups), attached to aromatic ring structures

Table 3 Minimal Fungicidal Concentration (MFC) of AC from Sida cordifolia L., and antifungal references (Nystatin and Clotrimazole)

\begin{tabular}{cccc}
\hline Microorganisms & $\begin{array}{c}\text { MFC }(\boldsymbol{\mu g} / \mathbf{m l}) \\
\text { AC of Sida cordifolia }\end{array}$ & $\begin{array}{c}\text { MFC }(\boldsymbol{\mu g} / \mathbf{m l}) \\
\text { Nystatin }\end{array}$ & $\begin{array}{c}\text { MFC }(\boldsymbol{\mu g} / \mathbf{m l}) \\
\text { Clotrimazole }\end{array}$ \\
\hline Candida albicans ATCC $\mathbf{9 0 0 2}$ & $33.33 \pm 14.43^{\mathrm{b}}$ & $16.67 \pm 7.22$ & $14.58 \pm 9.55$ \\
Candida albicans ATCC 2091 & $29.17 \pm 19.09^{c}$ & $12.5 \pm 0.00$ & $12.5 \pm 0.00$ \\
Candida parapsilosis ATCC 22019 & $41.67 \pm 14.43^{\mathrm{a}}$ & $14.58 \pm 9.55$ & $16.67 \pm 7.22$ \\
Candida krusei ATCC 6258 & $29.17 \pm 19.09^{c}$ & $12.5 \pm 0.00$ & $14.58 \pm 9.55$ \\
Candida tropicalis ATCC 750 & $33.33 \pm 14.43^{\mathrm{b}}$ & $14.58 \pm 9.55$ & $12.5 \pm 0.00$ \\
\hline
\end{tabular}


Table 4 Minimal Inhibitory Concentration (MIC) of combination of AC from Sida cordifolia L. and antifungal references (Nystatin and Clotrimazole)

\begin{tabular}{ccc}
\hline Microorganisms & MIC $(\boldsymbol{\mu g} / \mathbf{m l})$ combination of AC + Nystatin & MIC $(\boldsymbol{\mu g} / \mathbf{m l})$ combination of AC + Clotrimazole \\
\hline Candida albicans ATCC 9002 & $1.30 \pm 0.45^{\mathrm{a}}$ & $1.30 \pm 0.45^{\mathrm{b}}$ \\
Candida albicans ATCC 2091 & $1.04 \pm 0.45^{\mathrm{b}}$ & $1.30 \pm 0.45^{\mathrm{b}}$ \\
C. parapsilosis ATCC 22019 & $1.30 \pm 0.45^{\mathrm{a}}$ & $1.56 \pm 0.00^{\mathrm{a}}$ \\
C. krusei ATCC 6258 & $1.04 \pm 0.45^{\mathrm{b}}$ & $1.30 \pm 0.45^{\mathrm{b}}$ \\
C. tropicalis ATCC 750 & $1.04 \pm 0.45^{\mathrm{b}}$ & $1.56 \pm 0.00^{\mathrm{a}}$ \\
\hline
\end{tabular}

Values are Mean $\pm S D(n=3)$. Different letters in the same column indicate significant difference $(P<0.05)$ for $A C$.

of flavonoids, which enable the flavonoids to undergo a redox reaction that helps them to scavenge the free radicals [37]. So, it can be observed that the content of polyphenolic compounds of Sida cordifolia could be responsible for the radical scavenging activity. Thus, the restoration of the antioxidant defense system in this study may be due in part to the antioxidant activity of polyphenolic compounds [38]. In effect, the amount of DPPH scavenging activity in the majority of the plant extracts is attributed to the phenolic fraction [39]. In the present study, the scavenging of the DPPH radical may be attributed to its hydrogen-donating ability. Earlier workers have observed a direct correlation between antioxidant activity and the reducing power of certain plant extracts [40]. Certainly, the reducing property is generally associated with the presence of reductones, which exert antioxidant action by breaking the free radical chain by donating a hydrogen atom [40].

The results obtained in this study about antifungal activity indicate a considerable difference in antifungal activity of alkaloid compounds and in combination with antifungal references. About these findings, it is widely known that plants possess healing properties [41]. The best of our knowledge, this is the first report dealing with the interaction between alkaloid compounds with the chemical antimicrobial drugs currently in use. Synergy research in phytomedicine has established as a new key activity in recent years. It is one main aim of this research to find a scientific rational for the therapeutic superiority of herbal

Table 5 Fractional Inhibitory Concentration (FIC) and FICI of combination of AC from Sida cordifolia L. with Nystatin

\begin{tabular}{ccccc}
\hline Microorganisms & FIC $_{\mathbf{a}}$ & $\mathbf{F I C}_{\mathbf{b}}$ & $\mathbf{F I C l}$ & Effect \\
\hline C. albicans ATCC $\mathbf{9 0 0 2}$ & 0.12 & 0.31 & 0.43 & Synergistic \\
C. albicans ATCC 2091 & 0.12 & 0.25 & 0.37 & Synergistic \\
C. parapsilosis ATCC 22019 & 0.10 & 0.21 & 0.31 & Synergistic \\
C. krusei ATCC 6258 & 0.12 & 0.25 & 0.37 & Synergistic \\
C. tropicalis ATCC 750 & 0.10 & 0.25 & 0.35 & Synergistic \\
\hline
\end{tabular}

$\mathbf{F I C}_{\mathbf{a}}=$ MIC of AC in combination/MICa alone; $\mathbf{F I C}_{\mathbf{b}}=$ MIC of the antifungal agent in combination/ $\mathrm{MICb}$ alone and $\mathrm{FICl}=\mathrm{FIC}_{\mathrm{a}}+\mathrm{FIC}_{\mathrm{b}}$.

$a=$ alkaloid compounds; $b=$ Nystatin.

The FICl was interpreted as follows: (1) a synergistic effect when $\mathrm{FICl}=0.5$; (2) an additive or indifferent effect when $\mathrm{FICl}>0.5$ and $<1$; (3) an antagonistic effect when $>1$. drugs derived from traditional medicine as compared with single constituents thereof. Synergy effects of the mixture of bioactive constituents and their byproducts contained in plant extracts are claimed to be responsible for the improved effectiveness of many extracts and conventional antimicrobial drugs [42]. Such properties can be partly attributed to the diverse array of secondary metabolite such as alkaloids which are known to be essential for plants' defense against microbial attack or insect and animal predation [43]. Moreover, it is important to notice that over compounds such as alkaloids have strong antimicrobial activities [15]. Alkaloid compounds were very susceptible fungus probably because they act on mucopolysacharide capsule of fungal strains. In effect, the polysaccharide capsular material in some of the pathogenic microorganism is responsible for virulence and antimicrobial resistance [44]. It is the reason of difference in antifungal activity of alkaloid compounds and their combination with antifungal references. Recent studies showed that the alkaloids are known to have antimicrobial properties and [45] have reported about 300 alkaloids showing such activity.

As for the immunostimulatory capacity, results could be explained by the lack of biologically active antioxidants such as polyphenol compounds lowly contained in the alkaloid compounds. In effect, polyphenol compounds are considered as the major contributors to the antioxidant potential of plants [46], and antioxidant play an important role

Table 6 Fractional inhibitory concentration (FIC) and FICI of combination of $\mathbf{n}$-butanol fraction from Sida cordifolia L. with Clotrimazole

\begin{tabular}{ccccc}
\hline Microorganisms & FIC $_{\mathbf{a}}$ & $\mathbf{F I C}_{\mathbf{b}}$ & $\mathbf{F I C l}$ & Effect \\
\hline C. albicans ATCC $\mathbf{9 0 0 2}$ & 0.12 & 0.31 & 0.43 & Synergistic \\
C. albicans ATCC 2091 & 0.12 & 0.21 & 0.33 & Synergistic \\
C. parapsilosis ATCC 22019 & 0.10 & 0.25 & 0.35 & Synergistic \\
C. krusei ATCC 6258 & 0.12 & 0.31 & 0.43 & Synergistic \\
C. tropicalis ATCC 750 & 0.10 & 0.25 & 0.35 & Synergistic \\
\hline
\end{tabular}

$\mathbf{F I C}_{\mathbf{a}}=$ MICa alone $/ \mathrm{MIC}$ of $\mathrm{AC}$ in combination; $\mathbf{F I C} \mathbf{C}_{\mathbf{b}}=$ MICb of standard antifungal agent/MIC of the antifungal agent in combination and $F I C l=F C_{a}+F_{b}$. $a=$ alkaloid compounds; $b=$ Clotrimazole.

The FICl was interpreted as follows: (1) a synergistic effect when $\mathrm{FICl}=0.5$; (2) an additive or indifferent effect when $\mathrm{FICl}>0.5$ and $<1$; (3) an antagonistic effect when $>1$. 


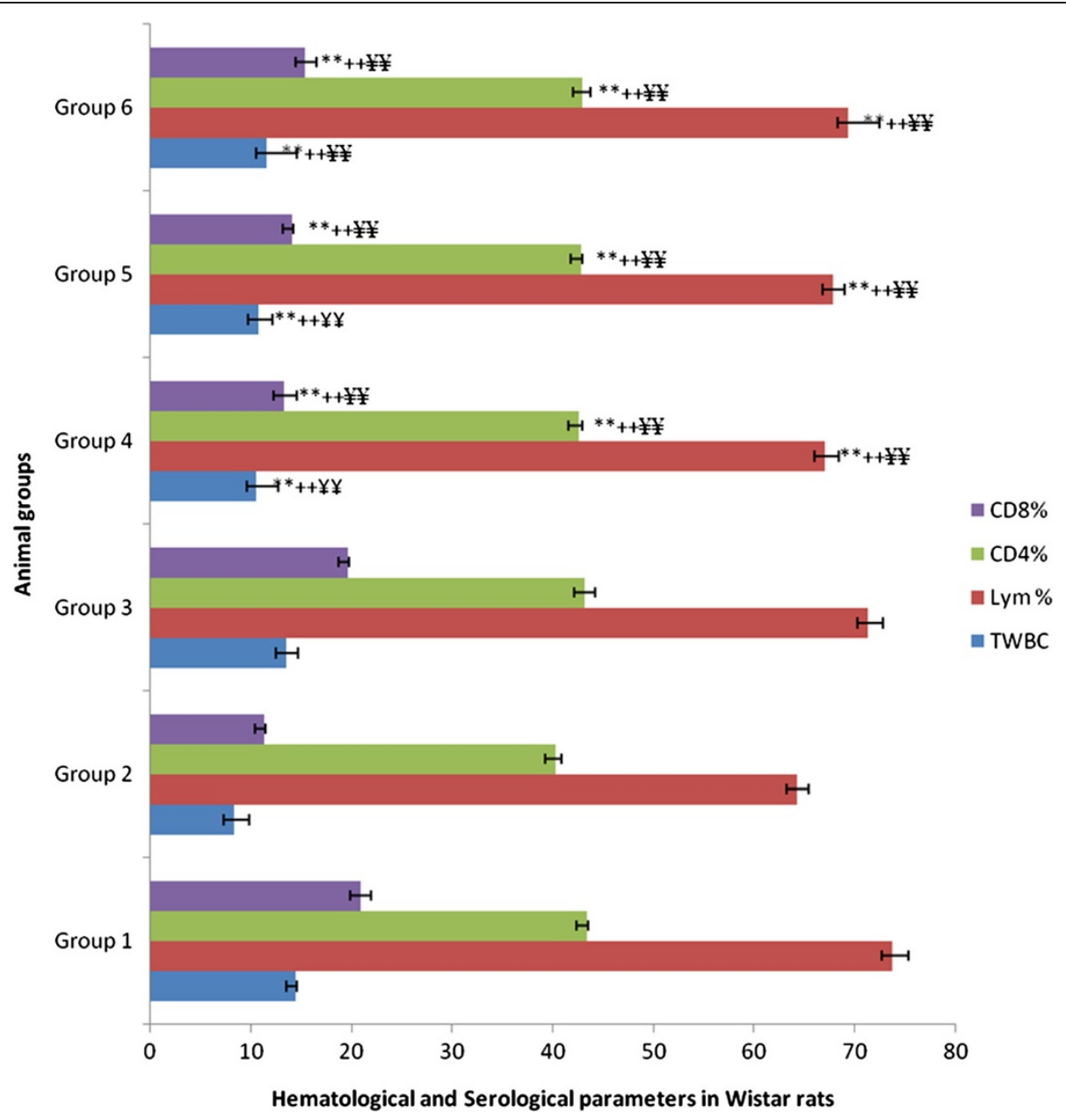

Figure 1 Effects of AC from Sida cordifolia L. on hematological and serological parameters in wistar rats. TWBC $\left(10^{3} / \mu l\right) ; \mathrm{Lym}=$ Total Lymphocytes. Values are mean \pm S.E.M. $(n=6)$ one-way ANOVA followed by Dunnett's $t$ - test: Compare all vs. control: **++ $¥ ¥ p<0.01$ compared with control groups (DMSO 10\%, Cyclosporin A and Concavanalin A). Group 1: rats received 10\% DMSO during 28 days. Group 2: rats received cyclosporin A $\left(25 \mathrm{mg} / \mathrm{kg} \mathrm{bw}\right.$.) from $1^{\text {st }}$ to the $7^{\text {th }}$ day and $10 \%$ DMSO from $8^{\text {th }}$ to the $28^{\text {th }}$ day. Group 3: rats received cyclosporin A (25 mg/kg bw.) from $1^{\text {st }}$ to the $7^{\text {th }}$ day and received Concavanalin A ( $25 \mathrm{mg} / \mathrm{kg}$ bw.) dissolved in $10 \%$ DMSO from the $8^{\text {th }}$ day to the $28^{\text {th }}$ day. Group 4: rats received cyclosporin A ( $25 \mathrm{mg} / \mathrm{kg}$ bw.) from $1^{\text {st }}$ to the $7^{\text {th }}$ day and received AC from Sida cordifolia $\left(50 \mathrm{mg} / \mathrm{kg} \mathrm{bw}\right.$.) dissolved in $10 \%$ DMSO from the $8^{\text {th }}$ day to the $28^{\text {th }}$ day. Group 5: rats received cyclosporin A (25 mg/kg bw.) from $1^{\text {st }}$ to the $7^{\text {th }}$ day and received AC from Sida cordifolia (100 mg/kg bw.) dissolved in $10 \%$ DMSO from the $8^{\text {th }}$ day to the $28^{\text {th }}$ day. Group 6: rats received cyclosporin A ( $25 \mathrm{mg} / \mathrm{kg} \mathrm{bw}$.) from $1^{\text {st }}$ to the $7^{\text {th }}$ day and received AC from Sida cordifolia (200 mg/kg bw.) dissolved in $10 \%$ DMSO from the $8^{\text {th }}$ day to the $28^{\text {th }}$ day.

in controlling oxidative stress and decreasing disease activity [47]. This relation could be responsible for reducing oxidative stress due to cyclosporin A. These biological antioxidants by inhibiting the action of cyclosporin A have an inhibitory effect on the highly specific $\mathrm{T}$ helper response, eliminating the primary cell response to antigen. Indeed, after binding to an intra-cytoplasmic cyclophilin receptor, it blocks the activation pathway and calcineurin-dependent transcription and consequently gene expression of cytokines required for immune response [48]. In this case, the low immunostimulatory effect observed is due by the action of alkaloid compounds which are not the bioactive antioxidant compounds being able inhibit the oxidative stress. Indeed, surely this low immune power could be also explained by the low bioavailability of the extracts administered orally. It is worth noting that the intestinal absorption of plant extracts through the intestinal absorption is often low and weak [49].

\section{Conclusion}

In conclusion, the screening of antioxidant, antifungal and immunostimulatory activities performed on alkaloid compounds from Sida cordifolia L. which was traditionally used as herbs shows that they are endowed with potentially exploitable antifungal activity. Further purification of the active compounds and their anticandicidal activity evaluation are therefore suggested for further studies. 


\section{Competing interests}

The authors declare that they have no competing interests.

\section{Authors' contributions}

$\mathrm{KK}$ and $\mathrm{MO}$ carried out the study and wrote the manuscript, ANL and AS supervised the work and the manuscript. BMB and LLS contributed to the manuscript corrections. All authors read and approved the final manuscript.

\section{Acknowledgement}

The authors think Prof. Millogo Rasolodimby from the plants Biology Department of the University of Ouagadougou for the botanically identified of plants.

\section{Author details}

'Laboratory of Animal Physiology, University of Ouagadougou, 09 P.O. Box: 848, Ouagadougou 09, Burkina Faso. ${ }^{2}$ Laboratory of Biochemistry and Applied Chemistry, University of Ouagadougou, 09 P.O. Box: 848, Ouagadougou 09, Burkina Faso. ${ }^{3}$ Laboratory of Plant Pathology, Faculty of Science, University of Science and Technology of Masuku, Franceville, P.O. Box: 943 , Franceville, Gabon. ${ }^{4}$ Laboratory of Animal Physiology, Electrophysiology and Pharmacology, Faculty of Science, University of Science and Technology of Masuku, P.O. Box: 943, Franceville, Gabon.

Received: 17 October 2012 Accepted: 16 December 2012

Published: 26 December 2012

\section{References}

1. World health Organization: The world health report. Life in the 21 st century: a vision for all 2. Measuring health. Geneva, Switzerland: World Health Organization; 1998:39-60

2. Keymanesh K, Hamedi J, Moradi S, Mohammadipanah F, Sardari S: Antibacterial, antifungal and toxicity of rare Iranian plants. Int J Pharm 2009, 5:82-85

3. Gupta M, Mazumder UK, Gomathi P: Evaluation of antioxidant and free radical scavenging activities of Plumeria acuminate leaves. J Biol Sci 2007, 7:1361-1367.

4. Trichopoulou A, Soukara S, Vasilopoulou E: Traditional foods. A science and society perspective. Trends Food Sci. Tech 2007, 18:420-427.

5. Rahman I: Antioxidant therapeutic advances in COPD. Ther Adv Respir Dis 2008, 2:351-374.

6. Gülçin I, Mshvilaladze V, Gepdiremen A, Elias R: Screening of antioxidant and antiradical activity of monodesmosides and crude extract from Leontice smirnowii Tuber. Phytomedicine 2006, 13:343-351.

7. Ram AJ, Bhakshu LM, Raju RRV: In vitro antimicrobial activity of certain medicinal plants from eastern india, used for skin diseases. J Ethnopharmacol 2004, 90:353-357.

8. Kumara PD, Jayawardane GL, Aluwihare AP: Complete colonic duplication in an infant. Ceylon Med J 2001, 46:69-70.

9. Zaika LL: Spices and herbs: their antimicrobial activity and its determination. J Food Safety 1975, 9:97-118

10. Cordell GA: Newroots for an old science. In Studies in natural products chemistry. Pharmacognosy 13: bioactive natural products (part a). Edited by Atta-ur-Rahman Basha FZ. Amsterdam: Elsevier; 1993.

11. Nacoulma OG: Medicinal plants and their traditional uses in Burkina Faso. Ph. D.Thesis. University of Ouagadougou: 1996:328.

12. Konaté $K$, Souza A: Polyphenol contents, antioxidant and antiinflammatory activities of Six malvaceae species traditionally used to treat hepatitis B in Burkina Faso. Eur J Sci Res 2010, 44:570-580.

13. Nielsen K, Heitman J: Sex and virulence of human pathogenic fungi. Adv Genet 2007, 57:143-173.

14. Zimmermann M: Ethical guidelines for investigations of experimental pain in conscious animals. Pain 1983, 16:109-110.

15. Karou D, Savadogo A, Canini A, Yameogo S, Montessano C: Antibacterial activity of alkaloids from Sida acuta. Afr J Biotechnol 2006, 5:195-200.

16. Lamien-Meda A, Lamien CE, Compaoré MMY, Meda RTN, Kiendrebeogo M, Zeba B, Millogo JF, Nacoulma OG: Polyphenol content and antioxidant activity of fourteen wild elible fruits from Burkina Faso. Molecules 2008, 13:581-594

17. Ihami G: Antioxidant activity of L-Adrenaline: An activity-structure insight. Chemico-Biological Interaction 2009, 179:71-80.
18. Ihami Gülçin: Antioxidant properties of resveratrol: A structure-activity insight. Innovative Food Science and Emerging Technologies 2010, 11:210-218.

19. Hinnebourg I, Damien Dorman HJ, Hiltunen R: Antioxidant activities of extracts from selected culinary herbs and spices. Food Chemistry 2006, 97:122-129.

20. Gülçin, Ilhami, Bursal, Ercan, Sehitoglu M, Hilal, Bilsel, Mine, Goren, Ahmet C: Polyphenol contents and antioxidant activity of lyophilized aqueous extract of propolis from Erzurum,Turkey. Food Chem Toxicol 2010, 48:2227-2238.

21. Konaté K, Hilou A, Mavoungou JF, Lepengué AL, Souza A, Barro N, Datté JY, M'Batchi B, Nacoulma OG: Antimicrobial activity of polyphenol-rich fractions from Sida alba L. (Malvaceae) Against cotrimoxazol-resistant bacteria strains. Ann Clin Microbiol Antimicrob 2012, 11:5. doi:10.1186/1476-0711-11-5.

22. Pujol V, Villard J: Research of antifungal substances secreted by higher fungi in culture. French Pharmaceut J 1990, 48:17-22.

23. NCCLS-National Committee for Clinical Laboratory Standards: Performance standard for anti-microbial susceptibilitytesting: eleventh informational supplement. Document M100-S11. Wayne, PA, USA: National Committee for Clinical Laboratory Standard; 2001.

24. Wolfe EF, Klepser ME, Pfaller MA: Antifungal dynamics of amphotericin B and fluconazole in combination against Candida albicans, effect of exposure time. Pharmacotherapy 1997, 17:189-189.

25. Rosata A, Vitali C, De Laurentis N, Armenise D, Millil MA: Antibacterial effect of some essential oils administered alone or in combination with Norfloxacin. Phytomedicine 2007, 14:727-732.

26. Miller LC, Tainter ML: Estimation of the ED50 and its error by means of logarithmic probit graph paper: In. Proc Soc Exp Biol Med 1944, 57:261-264.

27. Konaté K, Hilou A, Ouédraogo M, Dibala IC, Mavoungou JF, Lepengué AN, Souza A, Barro N, Batchi BM, Nacoulma OG: In vivo immunostimulatory effect of aqueous acetone extracts of Cienfuegosia digitata Cav. and Sida alba L. (Malvaceae) traditionally used to treat hepatitis B in Burkina Faso. Agric Biol J N Am. doi:10.5251/abjna.2011.2.12.1402.1408.

28. Okeke IN, Laxmaninarayan R, Bhutta ZA, Duse AG, Jenkins P: Antimicrobial resistance in developing countries. Part 1: Recent trends and current status. Lancet Infect Dis 2005, 5:481-493.

29. Patwardhan B: Ethnopharmacology and drug discovery. J. Etnopharmacology 2005, 100:50-52.

30. Cos $P$, Vlietinck AJ, Berghe DV, Maes $L$ : Antiinfective potential of natural products: How to develop a stronger in vitro proof of concept. J Ethnopharmacology 2006, 106:290-302.

31. Gonzalez CE, Venzon D, Lee S, Mueller BU, Pizzo PA, Walsh TJ: Risk factors for fungemia in children infected with human immunodeficienccy virus: A case-control study. Clin Infect Dis 1996, 23:515-521.

32. Barrett $D$ : From natural products to clinically useful antifungals. Biochem. Bioph. Acta 2002, 1587:224-233.

33. Abad MA, Ansuategui M, Bermejo P: Active antifungal from natural sources. ARKIVOC 2007, 7:116-145.

34. Konaté K, Souza A, Lamidi M, Djoba Siawaya JF, Batchelili B, Ella Mendene FH, Aworet Samseny RRR, Millogo-Rasolodimby J, Nacoulma OG: Biological and Toxicological effects of Aqueous Acetone Extract of Cienfuegosia digitata Cav. (Malvaceae) in Mice and Rats. Journal of Pharmacology and Toxicology 2011, 6(2):149-157.

35. Kiessoun $K$, Ouédraogo M, Mavoungou JF, Lepengué AN, Souza A, BM' B, Nacoulma OG: Pharmacological and Toxicological effects of Aqueous Acetone Extract of Sida alba L. (Malvaceae) in animals model. International Journal of Phytomedicine 2012, 4(1), doi:10.5138/ijpm.v4i1.481.

36. Nsimba RY, Kikuzaki H, Konishi Y: Antioxidant activity of various extracts and fractions of chenopodium quinoa and Amaranthus SSp. Seads. Food Chem 2008, 106:760-766.

37. Pari L: Arumugam Suresh: Effect of grappe 'Vitis vinifera L.) leaf extract on alcohol induced oxidative stress in rats. Food Chem Toxicol 2008, 46:1627-1634.

38. Regi RK, Sabu MC, Kuttan R: Hypoglycaemic effect of methanol extract of Phyllanthus amarus Schum and Thonn on alloxan-induced diabetes mellitus in animals and its relation with antioxidant potential. Indian J Exp Biol 2002, 40:905-909.

39. Porto C, Calligaris S, Celotti E, Nicoli MC: Antiradical properties of commercial cognacs accessed by DPPH test. J Agric Food Chem 2000, 48:4241-4245. 
40. Tejesvi, Kukkundoor R, Kini, Harishchandra S, Prakesh, Ven Subbiah, Hunthrike S, Shetty: Antioxidant, antihypertensive, and antibacterial properties of endophytic species from medicinal plants. Can J Microbiol 2008, 54:769-780.

41. Agbafor KN, Nwachukwu N: Phytochemical Analysis and Antioxidant Property of Leaf Extracts of Vitex doniana and Mucuna pruriens. Biochem Res Int 2011, 2011:4. doi:10.1155/2011/459839. Article ID 459839.

42. Williamson EM: Synergy and other interactions in phytomedicines. Phytomedicine 2001, 8:401-409.

43. Kido EA, Pandolfi V, Houllou-Kido LM, Andrade PP, Marcelino FC: Plant antimicrobial peptides: An overview of supersage transcriptional profile and a functional review. Curr Protein Pept Sci 2010, 11:220-230.

44. Hooper DC: Emerging mechanisms of fluoroquinolone resistance. Emerg Infect Dis 2001, 7:337-341.

45. Vijayasanthi M, Kannan V, Venkataswamy R, Doss A: Evaluation of the Antibacterial Potential of various solvent extracts of Acacia nilotica linn. Leaves. Hygeia J D Med 2012, 4(1):91-96.

46. Coulidiati TH, Millogo-Koné H, Lamien-Méda A, Yougbaré-Ziébrou M, Milogo Rasolodimby J, Nacoulma OG: Antioxidant and Antibacterial Activities of Two combretum species from Burkina Faso. Research Journal of Medicinal Plant 2011, 5(1):42-53.

47. Nourmohammadi I, Athari-Nikazm S, Vafa MR, Bidari A, Jazayeri S: Effect of Antioxidant supplementations on Oxidative stress in Rheumatoid Arthritis Patients. J Biol Sci 2010, 10(1):63-66.

48. Kronke M, Leonard WJ, Depper JM, Arya SK, Wongstaal F: Cyclosporin A inhibits $T$ cell growth factor gene expression at the level of mRNA transcription. Proc Natn Acad Sci USA 1984, 81:5214.

49. Obici S, Otobone FJ, da Siva Sela VR, Ishida K, da Silva JC: Preliminary toxicity study of dichloromethane extract of Kielmeya coriacea stems in mice and rats. J Ethnopharmacol 2008, 115:131-139.

doi:10.1186/1476-0711-11-33

Cite this article as: Ouédraogo et al:: Free radical scavenging capacity, anticandicidal effect of bioactive compounds from Sida Cordifolia L., in combination with nystatin and clotrimazole and their effect on specific immune response in rats. Annals of Clinical Microbiology and Antimicrobials 2012 11:33.

\section{Submit your next manuscript to BioMed Central and take full advantage of:}

- Convenient online submission

- Thorough peer review

- No space constraints or color figure charges

- Immediate publication on acceptance

- Inclusion in PubMed, CAS, Scopus and Google Scholar

- Research which is freely available for redistribution 